\title{
Co-development of conceptual understanding and critical stance, an essential condition for science learning
}

\section{Laurence Viennot ${ }^{1}$}

PRES Sorbonne Paris Cité, Université Paris Diderot, LDAR

France

E-mail: laurence.viennoteuniv-paris-diderot. fr

Since nearly two decades, a decline of interest in scientific studies has entailed the choice of new objectives for science teaching in many countries. To put it briefly, affective factors like motivation and the development of competences have received much attention. Consequently, new approaches to teaching, for instance Inquiry Based Science Education, have been widely implemented. Although multiple learning benefits are expected in each case, also for the future citizen, there is often, de facto, a trend toward less conceptual development and structuring, be it in teaching objectives or in students' achievements. Via an analysis of some teaching rituals, I will briefly discuss the risks of over-simplifying the physics content, and the need for developing a critical stance in students. I will then discuss, based on two investigations at upper secondary or university level (hot air balloon, radiocarbon dating), the idea that a competence like critical analysis should not be envisaged separately from a minimum conceptual development. The final discussion will bear on implications for teaching.

Frontiers of Fundamental Physics 14

FFP14

15-18 July 2014

Aix Marseille University (AMU) Saint-Charles Campus, Marseille

${ }^{1}$ Speaker

(C) Copyright owned by the author(s) under the terms of the Creative Commons Attribution-NonCommercial-ShareAlike Licence. 


\section{Introduction}

Many objectives are presently ascribed to the teaching of physics, ranging from students' engagement with science to the development of their critical sense and responsible citizenship, as well as a first comprehension of the nature of science. Students should understand that science aims at a unified theoretical description of the world and that consistent reasoning is needed to relate phenomena and theories.

Given students' decreasing numbers in many countries, the concern for attractiveness, in practice, has been particularly prominent, but promoters of methods which targeted this objective do not renounce the others. Thus, concerning Inquiry Based Science Education, the "Rocard" report [1] speaks of "... a pedagogy using an inquiry-based approach that succeeds in developing excitement about science" as well as "children's and students' interest and attainment levels", while Allende (2008) comments: “(...) through science education that is based on inquiry, an approach that reproduces in the classroom the learning process of scientists: formulating questions, doing experiments, collecting and comparing data, reaching conclusions, and extrapolating these findings to more general situations." [2]

On the other hand, a search for attractiveness goes with some risks, in particular that of oversimplifying the content at the expense of consistency, thereby losing sight of the unifying power of physical theories. In such a context, can we really hope to develop a competence like critical faculty in our students? This question is particularly vivid when competences are put forward, as is the case in France for instance, with a very weak structuring of the taught contents.

This talk is focused on this question. After a brief discussion of the risks linked to a search for simplicity, some experiments will be summed up to document the conditions in which university students can or not enact and develop their critical faculty, given their more or less complete understanding of the content under study.

\section{Simplifying to be attractive}

This talk is focused on this question. After a brief discussion of the risks linked to a search for simplicity, some experiments will be summed up to document the conditions in which advanced students can or not enact and develop their critical faculty, given their better or lower understanding of the content under study.

A common idea about teaching strategies is that "seeing is understanding" as if concepts were directly accessible in this way. The wish to "show" may inspire fruitful teaching strategies, but it often goes with insufficient cautions. Such is the case illustrated in Figure 1. Figure 1(a) seemingly shows visible light rays passing over the horizontal surface, in nice straight lines, just as they should: rectilinear propagation of light is the conceptual target of this very common device - a "ray box". This archetypal teaching tool is much in favor in classrooms and in museums. In Figure 1(b), the wavy lines made by the light bring the arrangement back to the category they should be in, i.e that of shadows. Each point of a trace of light is visible as a result of scattering of the received light, which got there via a rectilinear path not parallel to the surface. This reinterpretation also resolves a problem of consistency: how could the horizontal so-called "rays" not contain their source, located ten centimetres above the sheet? Clearly it is more simple not to argue about the ray boxes and use them to convince students of rectilinear 
propagation, as is currently done, but then we are seriously violating consistency. Moreover, we reinforce a common view that light would be visible "per se".
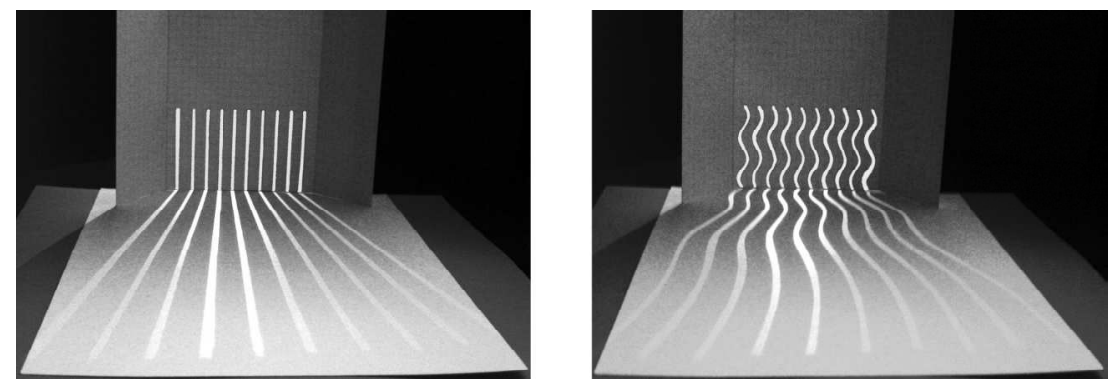

Figure 1 - (a) A small lamp behind a screen in which parallel slits have been cut, produces traces of light on the surface; arrangement (b) avoids oversimplification in this respect. In both cases what is seen is a set of shadows. Credit W. Kaminski

Another example, outlined in Figure 2, concerns a DVD aimed at promoting an interdisciplinary teaching in lower secondary education using inquiry based teaching.

\section{A problematic situation: How to protect against cold ?}

A student : emergency blanket ... aluminium

All agree

Some experiments with various materials:
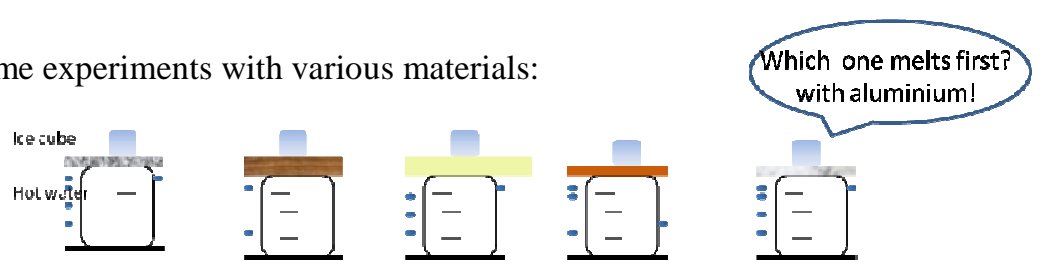

Conclusion : With aluminium, you cannot protect against cold. No comment

Radiant process ignored

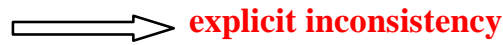

Figure 2. Uncontrolled generalization: outline of a videotaped sequence [3] intended to promote an interdisciplinary teaching in lower secondary education in France: "Enseignement Intégré de Science et Technologie" [4]).

With this example we observe the risks attached to an oversimplified analysis ending up with overgeneralization. The case of thermal properties of materials is complex. Several phenomena can occur simultaneously, i.e. conductive, convective and radiant processes. Here, having ignored the weak radiant coefficient of aluminium led the teacher into blatant contradiction. It is tempting to have pupils perform simple experiments but as soon as a generalization is discussed, it is imperative to be very cautious. And of course, when coming across a contradiction, it is no less important to recognize it and acknowledge that a single experiment is not enough to reach any sound general conclusion in science. 
These two examples underline to which extent teachers and students need to develop their critical faculty, all the more so, paradoxically, when the teaching landscape is framed by a strong desire to "show" and simplify physics in order to motivate students.

\section{Enacting critical faculty $\mathrm{V} / \mathrm{s}$ understanding the topic: two investigations}

Two small investigations will now be summed up, in order to document this question: how students with weak conceptual command of a topic can enact, or not, their critical faculty about explanations concerning this topic? The question is posed for a case that would not be just obvious: "Weak command" means here that it is in principle sufficient to formulate some questions, but still very incomplete to have a feeling of comprehension. Note that in the context briefly described afore, this situation prevails in students' learning time.

\subsection{The hot air balloon}

The topic involved in this first example might have served as an example in the previous section, in that it is linked to a typical teaching ritual.

With a touch of irony, we can define an "instructional hot-air balloon". For such a balloon, the envelope open at the base defines an internal space of volume $V$, within which the air is at temperature $T_{i n t}$ and pressure $p_{\text {int }}$. The whole thing, including passengers but excluding the internal air, has mass $M$. We should simplify, and temporarily forget, for example, the turbulence generated by the burners. The outside must also be defined: air at atmospheric pressure ( $p_{\text {ext }}=$ $p_{0}$ ) and at temperature $T_{e x t}$. Very frequently (see for example [5]), equality of internal and external pressures are added to the model $\left(p_{\text {int }}=p_{\text {ext }}=p_{0}\right)$, the rationale being that the envelope is open.

A standard solution relies on Archimedes' principle and starts with a Newtonian balance which brings to bear the weight of solid materials and that of two identical volumes of air. These masses depend on densities of air - internal and external - which themselves depend on respective temperatures (then the perfect gas relationship is used), knowing that pressures are the same for both. In four lines of working facilitated by the equality of the pressure terms, temperatures (via their reciprocals), problem data can all be linked together. We are then in a position to know to what temperature the internal air must be heated to achieve lift-off, and subsequent stability once in the air.

However, this approach, unless accompanied by further discussion, is very problematic. If there were the same pressure inside and outside near each small part of the envelope, it follows that no net force is exerted by all of the gas. Then there can be no up-thrust. The balloon must simply fall to the ground due to its weight. One can also use an argument of symmetry to predict this sad end. If internal and external pressures were the same everywhere, no particular spatial direction would be preferred by these gases: why should they push upwards?

In fact, using Archimedes' principle is to make use of the sine qua non of its relevance, namely the existence of pressure gradients, essential for hydrostatic problems where gravity is present. Between the level of the opening and that at the top of the balloon, the pressure of the air falls. However, as this is less dense, the pressure from bottom to top falls less quickly on the 
inside than on the outside. Starting from a value assumed identical at the level of the opening, the internal and external pressures are not equal elsewhere, in particular at the top of the balloon: the highest pressure is on the inside. Hence the fact that the envelope can be inflated and held up despite the weight of the whole thing. This analysis is summarised in Figure 3. The global analysis supported by the gradient theorem and its consequence in fluid statics (the expression for the Archimedes' interaction) unites the mechanical (local and more direct) balance of forces in play.

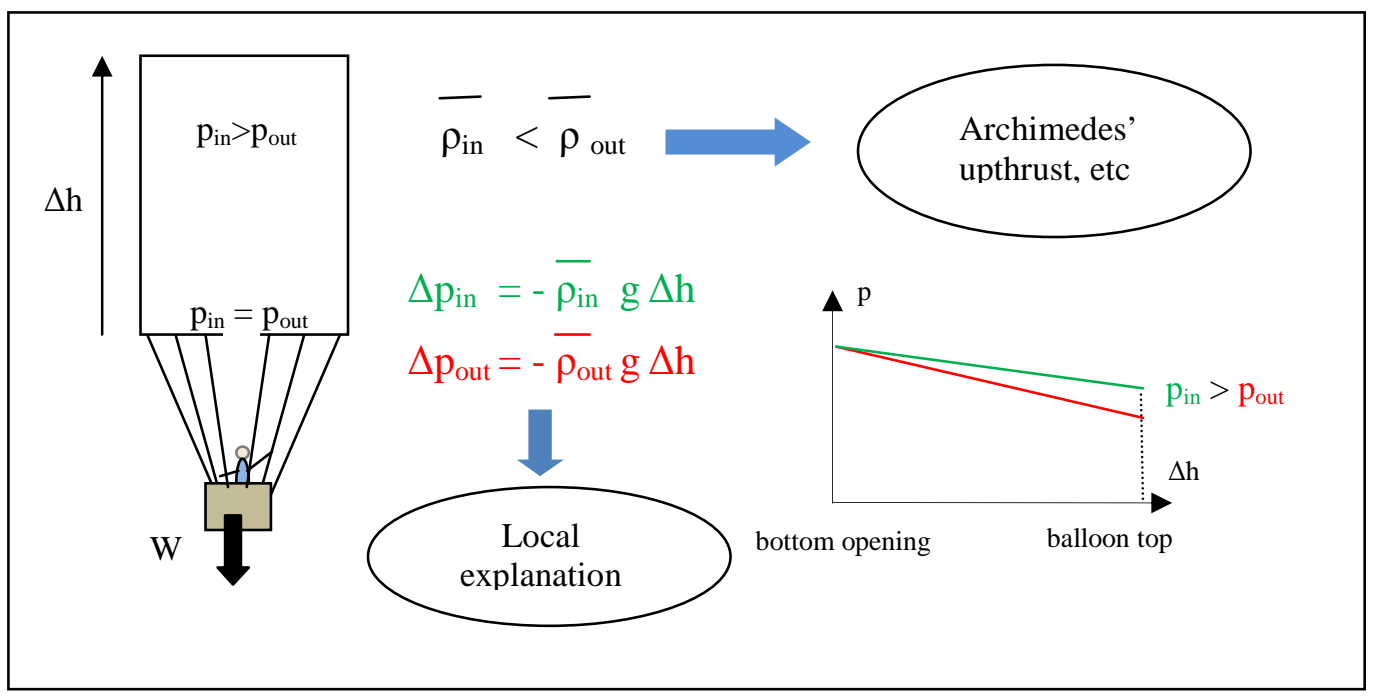

Figure 3- Elements for understanding how a balloon is held up, here shown as a cylinder to facilitate understanding the effect of pressure forces on the envelope

What is striking in this case is that the faulty hypothesis is not only a matter of neglecting a fourth decimal in the variations of pressure, it is a blatant deny of the very foundation of fluid statics: the existence of pressure gradients.

Several investigations [6] were intended to document teachers' and students' response when confronted to the ritual explanation. Teachers $(\mathrm{N}>100)$ did not spontaneously detect the slightest problem. Concerning the students, the question was: Will they enact their critical sense? And what will be their response after an interactive dialogue based on the analysis summed up afore? A first series of interviews with 15 first year university students showed that, when asked if they would improve the current statement of the problem, they did not pinpoint the inconsistent hypothesis. Instead, they centred their remarks on gases which would be more or less "perfect". In contrast, after a discussion of reasons for criticising this hypothesis, they reacted strongly. They unanimously claimed that this type of discussion was highly valuable, despite the time it takes (half an hour) adding comments like:

-Why is it the first time someone tells me this?

-You made me think: thank you.

We went on with an investigation with 14 future journalists and science mediators, in third year at university, having previously obtained a scientific diploma [7]. The objective was analogous: Would they criticize a popularization paper explaining how a hot air balloon works based on the current hypothesis, given that they all knew enough physics to use the counterarguments explained afore? All along the discussion, they had opportunities (first line in Table 
1) to criticize the paper, be it about the way it is written $\left(\mathrm{C}_{0}\right.$ in Table 1$)$ or for inconsistent explanation (C). They got aware (A) of the incoherent hypothesis at different steps of the interview, but there was often an important delay between this first event and their explicit critique of the paper itself. What was prevalent in the first phases was a search for vanishing memories, until they shifted toward a search for comprehension. When they finally decided to criticize the writer, they did it very explicitly and they showed able retrospectively to comment on their own attitude.

- By simplifying things, you deform reality.

-Well, it's true that when you read that (she shows the article), you swallow it without asking yourself any questions about the physical reality.

Table 1. Steps in students' intellectual paths: Awareness of the inconsistency and a critical attitude.

\begin{tabular}{|c|c|c|c|c|c|c|c|}
\hline $\begin{array}{c}\text { Name and } \\
\text { "scientific origin" } \\
\alpha: \text { architecture } \\
\beta \text { : biology } \\
\mu: \text { mathematics } \\
\text { : technology } \\
\varphi: \text { physics }\end{array}$ & $\begin{array}{l}\text { From } \\
\text { the start }\end{array}$ & $\begin{array}{l}\text { First oral } \\
\text { question } \\
\text { about the } \\
\text { assumption }\end{array}$ & $\begin{array}{c}\text { Argument } \\
\text { of symmetry } \\
\text { Uniform } \\
\text { pressure }\end{array}$ & $\begin{array}{c}\text { Local } \\
\text { explanation } \\
\text { Same } \\
\text { pressure on } \\
\text { both side of a } \\
\text { small part of } \\
\text { the envelope }\end{array}$ & $\begin{array}{c}\text { Origin of } \\
\text { Archimedes' } \\
\text { up-thrust and } \\
\text { link with the } \\
\text { pressure } \\
\text { gradient }\end{array}$ & $\begin{array}{c}\text { Plotting the } \\
\text { graph }\end{array}$ & $\begin{array}{l}\text { When } \\
\text { asked if } \\
\text { they felt } \\
\text { able to } \\
\text { explain }\end{array}$ \\
\hline Ludovic $(\beta)$ & $\mathrm{C}_{0}$ & $\mathrm{~A}$ & $\mathrm{~A}$ & & & $\mathrm{~A}$ & $\mathrm{C}$ \\
\hline Laurence $(\beta)$ & $\mathrm{C}_{0}$ & $\mathrm{~A}$ & & $\mathrm{~A}$ & $\mathrm{~A} / \mathrm{C}$ & A & \\
\hline Carine $(\beta)$ & & & A & & & $\mathrm{A} / \mathrm{C}$ & \\
\hline Adeline $(\varphi)$ & & & $\mathrm{A}$ & & & $\mathrm{A} / \mathrm{C}$ & \\
\hline Céline $(\beta)$ & & & & $\mathrm{A} / \mathrm{C}$ & & & \\
\hline Anna $(\mu)$ & & & & $\mathrm{A}$ & & $\mathrm{A} / \mathrm{C}$ & \\
\hline Marion $(\varphi)$ & $\mathrm{C}_{0}$ & & & $\mathrm{~A}$ & & $\mathrm{~A}$ & $\mathrm{C}$ \\
\hline Emmanuelle $(\alpha)$ & $\mathrm{C}_{0}$ & & & & $\mathrm{~A}$ & $\mathrm{~A} / \mathrm{C}$ & \\
\hline Laura $(\varphi)$ & & & & & $\mathrm{A}$ & $\mathrm{A}$ & $\mathrm{C}$ \\
\hline Thomas $(\varphi)$ & & & & & & $\mathrm{A}$ & $\mathrm{C}$ \\
\hline
\end{tabular}

'A' indicates when the students clearly showed their awareness of the inconsistency.

' $\mathrm{C}_{0}$ ' indicates some signs of a critical attitude from the start, not yet focused on the assumption.

' $\mathrm{C}$ ' indicates when the students first used their awareness of the inconsistency to criticize the article or to retrospectively criticize their own attitude during the interview.

Thus, students who first had seemed unable of any critique turned out to adopt a clear critical attitude. This happened when they reached themselves more command of the topic.

With this preliminary result in mind, we carried out a second type of experiment, more explicitly structured to analyse students' intellectual pathways when confronted to incomplete explanations. 


\subsection{Radio carbon dating}

With this experiment ([8], [9], [10]), we aim at documenting in more detail the possible links between student's developing conceptual understanding of a topic and their ability to express their frustration, when presented with very incomplete explanations, or their intellectual satisfaction in the opposite case. We took the topic of radio carbon dating, because it was likely to sound familiar to our interviewees - ten prospective teachers in $4^{\text {th }}$ year at university - while being in fact rather complex.

\subsubsection{Content analysis}

Such a topic may be dealt with at different levels of completeness. We chose to characterize a first level of comprehension that would be self-consistent. This "minimal explanation" is quite close to, although more explicit than, that presented by Libby in the address he gave when he was awarded the Nobel medal (1960) [11]. In the following content analysis, we italicized a series of crucial conceptual nodes that will be used further in our methodology.

Radiocarbon dating is based on two observations: one is that the proportion of ${ }^{14} \mathrm{C}$ (relative to ${ }^{12} \mathrm{C}$ ) is uniform and constant over time in the atmosphere and the other one is that it decreases in dead organic matter. We assume here that the proportion of ${ }^{14} \mathrm{C}$ in the atmosphere is equal to that in the living organic matter (which implies that exchanges between atmosphere and living beings do not depend on the carbon isotope). The number of ${ }^{14} \mathrm{C}$ atoms decreases according to a known law, here an exponential decay law: $N_{C}(t)=N_{0} \exp \left(-\lambda_{2} t\right)$. This law can be used to compute the time that elapsed between the body's death and the time the sample is collected, provided that we know $N_{0}$ (number of atoms of ${ }^{14} \mathrm{C}$ in the body at death time). The fact that ${ }^{14} \mathrm{C}$ concentration is broadly constant in the atmosphere (assumption made by Libby) is related to equal time rates of formation and disintegration. Such an equality is not accidental. ${ }^{14} \mathrm{C}$ is formed thanks to the action of "cosmic" neutrons on nitrogen atoms. When ${ }^{14} \mathrm{C}$ decays, it gives rise back to nitrogen.Thus, if we consider the total sum of all nitrogen (population 1) and ${ }^{14} \mathrm{C}$ (population2) atoms of the atmosphere, this sum is constant. The ${ }^{14} \mathrm{C}$ time rate of decay $\left(\frac{d N_{C}}{d t}\right)$ is multiplicative (it is given by the product of the number of ${ }^{14} \mathrm{C}$ atoms by the probability of decay by unit of time). Thus, this time rate adjusts until the total number of atoms of ${ }^{14} \mathrm{C}$ in the atmosphere reaches a steady state. To understand this, assume that the population of C14 and N14 are respectively greater and smaller than at steady state. Then the time rates of decay and formation of $\mathrm{C} 14$, due to multiplicative structure, become respectively greater and smaller. As a result, the net time rate of change of $\mathrm{C} 14$ is negative and the population of $\mathrm{C} 14$ decreases. This process continues until the two time rates adjust.

\subsubsection{The interviews}

The interviews where framed on a series of five texts (T1 to T5) found on the internet or in popularization literature, plus a final explanation by the interviewer (we call this "text" T6 in 
what follows). Starting from a very incomplete argument (T1, discussed in Step 1)), the interviewees are successively presented with more and more complete explanations (Steps 2 to 5) until Step 6, with T6, during which they are confronted with an analogy and complementary explanations. At this step, they have been presented with all the arguments that are necessary to grasp the "minimal explanation" displayed in the previous section. Table 2 shows which of the crucial elements of explanation pinpointed above (in italics in previous section: content analysis) are added each time to the preceding text in the considered series.

After a brief dialogue about their knowledge of radio carbon dating, the interviewees are asked, at each step, about their response to the corresponding text: do they consider it a satisfying explanation, do they need more arguments and why? A final step consists in asking students for their global evaluation of the teaching interview, their feeling at the end. Students are asked to formulate their level of satisfaction, to be rated from 1 (poor) to 4 (very high), or to express it in a sentence should they prefer to.

Table 2. The texts used in the interviews: arguments successively introduced, this is done explicitly $(\mathrm{X})$, or a hint is provided (x)

\begin{tabular}{|c|c|c|c|c|c|c|}
\hline arguments & $\mathrm{T} 1$ & $\mathrm{~T} 2$ & T3 & $\mathrm{T} 4$ & T5 & T6 \\
\hline${ }^{14}$ C decay after death; known law. & $\mathrm{X}$ & & & & & \\
\hline $\begin{array}{l}\text { Creation process: « cosmic » neutron on } \\
\text { nitrogen }\end{array}$ & $\mathrm{X}$ & & & & & \\
\hline Need: $\mathrm{N}_{0}$ death known & & $\mathrm{x}$ & & & & \\
\hline Exponential decay law & & $\mathrm{X}$ & & & & \\
\hline $\mathrm{C} / \mathrm{C}$ in living beings is constant in time & & $\mathrm{X}$ & $\mathrm{X}$ & & & \\
\hline $\begin{array}{l}\text { Rate of creation }\left(\mathrm{d} \mathrm{C}^{14} \mathrm{dt}\right) \text { is constant in } \\
\text { time }\end{array}$ & & & $\mathrm{X}$ & & & \\
\hline Same rate $->$ Steady state & & & & & $\mathrm{X}$ & \\
\hline Transit. regime, adjustment & & & & & $\mathrm{x}$ & $\mathrm{X}$ \\
\hline $\mathrm{N}$ and ${ }^{14} \mathrm{C}:$ sum is constant in time & & & & & & $\mathrm{X}$ \\
\hline $\begin{array}{l}\text { Multiplicative } 14 \mathrm{C} \text { decay rate. Adaptation } \\
\text { through factor } \mathrm{N}_{0}\end{array}$ & & & & & & $\mathrm{X}$ \\
\hline
\end{tabular}

* This argument is not stated in the text but is provided by the interviewer in case the student ignores it.

\subsubsection{Meta-cognitive-affective aspects: our categories}

We focused on students' critical attitude, their awareness of their own comprehension, their intellectual satisfaction or frustration, aspects which are potentially entangled: "metacognitive-affective" aspects ( $m c a$ ) in what follows.

We pinpointed cases where they express their satisfaction of getting additional information about a topic (code in Table 3: $\mathrm{m}^{+}$), for instance:

- I think it is what I was missing to know exactly how it works. I think I had forgotten.

\footnotetext{
${ }^{2}$ Should a student raise a question about this point, the interviewer states isotopic independence during exchanges between atmosphere and living things
} 
or , in contrast, when they express their frustration about insufficient explanation $\left(\mathrm{m}^{-}\right)$, for instance:

- It poses a problem more than it solves ...

The level of their possible agreement at the end of the discussion of each given text may be considered total (code in Table $3: \Theta$ ):

-It's very complete.

or half-heated (code in Table $: \approx$ ):

-Well, is that sufficient ? Actually, it gives ... It doesn't explain everything, but actually it gives an idea, after that ...

Special attention is given to the type of question they pose during the discussion. A distinction is made between two types of questions. Some questions bear on one of the "crucial items" listed in our content analysis. They are referred as crucial question (cq), thus:

- Is that a necessity ? Had it to reach a state of equilibrium, or is it just by chance that rates of formation and decay coincide? I 'm stuck!

Other questions bear on a point which is not included in the list of crucial items (a "detail": dl), thus:

- (...)but with a detector, yes, but how does it work, actually, the detector?

Table 3. Main thematic categories concerning the meta-cognitive affective aspects.

\begin{tabular}{cc}
\hline Thematic category $(\mathrm{mca})$ & Code \\
\hline Agreement at the end of a step & $\Theta$ \\
\hline Half-hearted agreement at the end of a step & $\approx$ \\
\hline Question posed about a detail & $\mathrm{dl}$ \\
\hline Question posed about a "crucial" point & $\mathrm{cq}$ \\
\hline Satisfaction after additional information & $\mathrm{m}+$ \\
\hline Frustration because of insufficient explanation & $\mathrm{m}-$ \\
\hline
\end{tabular}

\subsubsection{Meta-cognitive-affective aspects: main results}

The coding of students interviews concerning $m c a$ aspects is displayed in Tables 4 and 5 . Table 4 displays students' level of agreement at the end of each step and the types of questions posed, Table 5 also displays their level of agreement but this time with the statements expressing satisfaction or frustration. We ranked the students in Table 4 according to the step during which they first posed a crucial question and we kept the same order for Table 5.

We observe that, save for the two last students, the same "diagonal" (broadly speaking, from col. 3, line 2 to col. 6, line 9) divides the tables in two parts. Concerning the questions posed (Table 4), there is no surprise in finding only questions about details on the left of the diagonal because the table was constructed following this rule. In contrast, it is worth noting that, left of the same diagonal, what dominates is agreement or half-hearted agreement, though incomplete the explanations may be. 
In most cases of half hearted agreement, students pose various questions about points which - from our point of view - are not crucial at this step, e.g. the way a detector works (irrelevant here), the exact mathematic expression of the law of decay (whereas in any case the starting point is needed), etc. Concerning their intellection satisfaction, we observe that with each text, in cases displayed left of the same diagonal, the students most often express their satisfaction for receiving new pieces of information, this without any real critique concerning the previous explanation.

Table 4. Level of agreement at the end of each step and type of questions posed.

Notations: $\Theta, \approx$ : agreement, half-hearted agreement; dl: question about «details »; cq: crucial question; $m+:$ satisfaction with a new piece of information; $m$ - : frustration. Last column: scale from 1 (low) to 4 (high)

\begin{tabular}{|c|c|c|c|c|c|c|c|}
\hline & $\mathrm{S}_{1}$ & $\mathrm{~S}_{2}$ & $\mathrm{~S}_{3}$ & $\mathrm{~S}_{4}$ & $\mathrm{~S}_{5}$ & $\mathrm{~S}_{6}$ & $\mathrm{~S}_{7}$ \\
\hline Lamb & $\approx \mathrm{dl}$ & $\approx \quad \mathrm{dl}$ & & $c q^{2}$ & & $\Theta$ & 3 \\
\hline Olli & $\Theta$ & $\Theta$ & $\Theta \mathbf{d l}$ & $c q$ & $c q$ & $\Theta$ & 3 \\
\hline lago & $\approx \mathrm{dl}$ & $\approx \mathrm{dl}$ & $\Theta$ & & $\approx$ & $\Theta$ & 2 \\
\hline Boul & $\approx$ & $\Theta$ & $\Theta$ & & cq & $\Theta$ & 2,5 \\
\hline Vivi & $\Theta$ & $\Theta$ & $\Theta \quad$ dl & $\approx$ & $c q^{2}$ & $\Theta$ & 3 \\
\hline Tann & $\approx \mathrm{dl}$ & $\Theta \quad$ dl & $\Theta$ & $\Theta$ & $\Theta$ & $\Theta$ & 4 \\
\hline Thib & $\Theta$ & $\Theta \quad$ dl & $\Theta \quad \mathbf{d l}^{2}$ & $\Theta$ & $(\Theta)$ & $\Theta$ & 4 \\
\hline
\end{tabular}

Table 5. Level of agreement at the end of each step and statements expressing satisfaction or frustration. Notations: $\Theta, \approx$ : agreement, half-hearted agreement; $m+$ : satisfaction with a new piece of information; $m-$ : frustration.

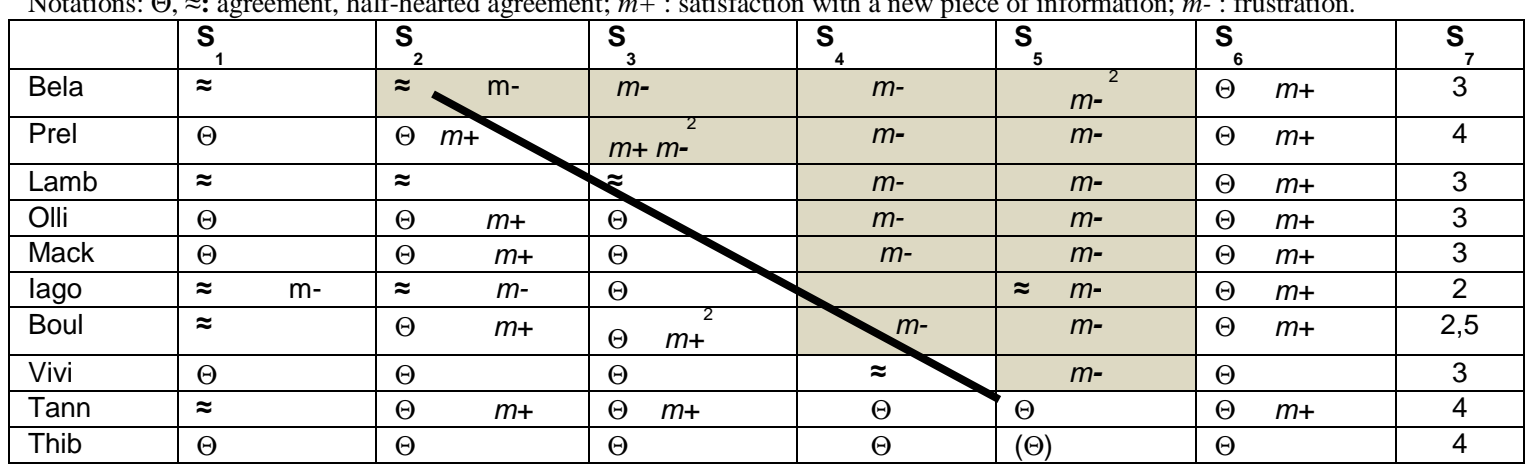

In contrast, on the right of the diagonal, in a "V" shaped domain of the tables, we observe no expression of agreement, and much frustration, along with crucial questions only.

Briefly put, these tables and the students' comments strongly suggest that at a given moment of the discussion, the interviewee appropriates the problem, gets aware that a more complete explanation is needed, takes some distance vis à vis the texts under study, poses "crucial" questions and really starts arguing, with sometimes retroactive self-critique. It seems as if a certain level of understanding concerning the topic under study triggered this change. At this stage the students' comprehension of the topic may be still very incomplete, but with a better appreciation of some crucial aspects of the problem. We might say, still hypothetically, that most of students needed to reach a threshold of comprehension - not the same for all before they feel a need for, and dare to, express their frustration, as sketched in Figure 3. In that sense, we could speak of a co-development of conceptual understanding and critical attitude. 
Incidentally, a certain level of understanding is a necessary condition but it is not sufficient, as witnessed by the two last students (Tables 4 and 5), who knew the topic very well previously and turned out to be unable to criticize the incomplete texts, happy as they were to feel at ease with their own comprehension.

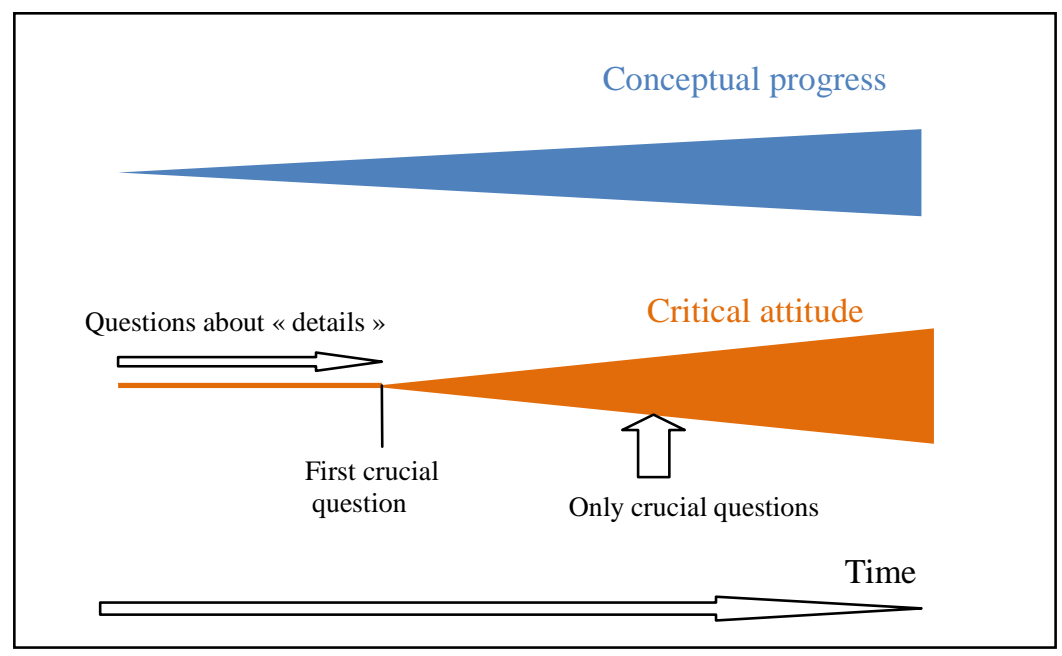

Figure 3. A tentative model for the co-development of conceptual understanding and critical attitude during the interviews.

\section{Recapitulation and final remarks}

Given the multiple objectives presently ascribed to the teaching of physics, and the current stress on the development of competences at the expense of conceptual structuring (as in France in secondary education), this talk started with caveats concerning the risks of oversimplifying the taught content. Several examples showed how our teaching rituals, like with "ray boxes" or exercises about a hot air balloon, could seriously put consistency at risk. A document issued by academic authorities also showed that the wish to show how science works, if not accompanied by thorough precautions, could entail over-simplified reasoning, hence blatant internal contradictions. Paradoxically, simplifying physics to be attractive is not simple at all, it requires utmost attention. Of course we should not "say everything" from the start and we have to simplify physics for teaching, but this process should be kept under control. In less academic words, we should avoid those "toxic" hypotheses which "kill" either the phenomenon, or consistency, or both.

In this context, critical faculty is not only one of the competences most often called for, it is also highly needed for all, teachers as well as students, in order to resist the facilities of "easy physics" and make the best possible use of the existing materials. But can it develop without a conceptual basis?

We chose to document the question of the relationships between conceptual development and critical attitude. Several small but converging investigations converged to suggest that these relationships are strong. At least for most of our interviewees, when confronted with incomplete or inconsistent explanations, we observed that the first phase of the interaction was characterized by a soft agreement, often with vague recognition of old memories, and various 
questions they posed in order to complete this reminding process. Then, after what appears as a threshold of comprehension, and of dissatisfaction as well, a series of crucial questions was posed, giving the impression that the student appropriated the search for a consistent explanation, while expressing more or less clearly his or her dissatisfaction. It seems as if interviewees' critical potential was freed, so that a search for intelligibility replaced a search for memories.

This type of intellectual process cannot be explained, we think, on the basis of a competence, i.e. critical faculty, that would be there or not in the students' panoply of intellectual tools. Students start enacting some potentialities at a given step, potentialities which were blocked previously, probably widely due to a feeling of conceptual unsufficiency. But their critical faculty did not rise out of nowhere. In this sense, it is probably very inappropriate to claim that students have no critical faculty and just "swallow" everything they are told. At the same time, with this kind of interactive pathway, their critical potential is not just suddenly enacted but the discussion contributes to develop this ability. Moreover, as they often comment, students appreciate consistency and express their satisfaction when they have progressed in this respect. To put it briefly, critical thinking and conceptual understanding should not be taught separately. A minimum conceptual structuration is needed if we want to foster critical thinking in our students. More generally, the way a given potential of critique is enacted or not may strongly depend on students' evolving comprehension of a topic, and, reversely, this potential is likely to develop via intellectual pathways which involve conceptual as well as meta-cognitive and affective aspects.

These remarks may see close to obviousness, but we also observe that, in many countries, the objective of developing competences "per se" might well be responsible for a regrettable situation, as described in several recent reports. Thus:

These students ... (France, end of upper secondary education 2013) see physics as disordered and anarchical. [12]

Or else, in a nordic context:

In our search for a possible explanation for the strikingly parallel decline in physics achievements for the «specialist» at upper secondary school, we have established a set of possible factors.(...) Several reports have pointed out that many students do not see the connection between the mathematics in the math class and the mathematics they actually use in physics (...). [13]

These reports all the more incite us to stress a view of science as aiming at a unified theoretical description of the world. This standpoint means we should actually underline conceptual coherence and links in teaching, keeping in mind the role of mathematics. There are some hints in our investigations which suggest that students' satisfaction does not stem exclusively from surprising experiments or "whaaouh" effects, but can also result from thorough understanding of the broached topics. We might therefore aim at reconciling various reasons for liking science. In the same line, we should put into perspective the merits of any "method" if understood as independent of the content. Positively, there is much to do to propose various approaches and means to be used in class practice, thus enlarging the range of teachers' choices.

For instance, a second contribution is reported in these proceedings (Viennot, these procedings), to illustrate a kind of teaching scenario- "concept-driven interactive pathways" 
([14], [15]) - which aims at a co-development of comprehension and critical faculty, and relies on the consideration of conceptual links, beyond the use of simple experiments. Materials posted on the MUSE web site (EPS-More Understanding with Simple Experiments [16]) are inspired by the same objectives (see also [17]).

\section{References}

[1] Y. Rocard, Science Education Now Report EU22-845, European Commission, Brussels (2007) http://ec.europa.eu/research/science-society/document_library/pdf_06/report-rocard-on-scienceeducation_en.pdf

[2] J.E. Allende, Academies Active in Education, Science (2008), 321 (1133)

[3] Académie des sciences, MEN, DGESCO, Séance de classe au collège des Ancizes. In Apprendre la science et la technologie au collège, 6me-5me. DVD vidéo, SCEREN (CNDP-CRDP), Paris (2010).

[4] Ministère de l'Education Nationale, Un enseignement intégré de science \& technologie au collège (6e et 5e). Guide de découverte. Paris : Académie des sciences, Académie des technologies, (2011).

[5] D.C. Giancoli, Physics (6th ed): Instructor Resource Center CD-ROM, Prentice Hall (2005).

[6] L. Viennot, Teaching rituals and students' intellectual satisfaction, Phys. Educ. 41 (2006), 400-408.

[7] S. Mathé \& L. Viennot, L. Stressing the coherence of physics: Students journalists' and science mediators' reactions, Problems of education in the 21 st century. 11 (11) (2009), 104-128.

[8] L. Viennot \& N. Décamp, Analysing texts about radio carbon dating: co-development of conceptual understanding and critical attitude, oral presentation, ESERA, Nicosie (2013).

[9] N. Decamp. \& L. Viennot, Prospective physics teachers' understanding of radio carbon dating: a teaching experiment. Oral presentation Teaching/Learning Physics. Integrating Research into Practice, GIREP, Palermo (2014)

[10] N. Décamp \& L. Viennot, Co-development of conceptual understanding and critical attitude, Analysing texts on radio-carbon dating, International Journal of Science Education, submitted (2014).

[11] W. F. Libby, "Nobel Lecture: Radiocarbon Dating", In Nobel Lectures, Chemistry 1942-1962 (1964), Elsevier Publishing Company, Amsterdam.

[12] T. Zabulon, On the linking between secondary teaching and higher education in physics and chemistry, 61e National Conference of Union of Physics and Chemistry Teachers (UdPPC) Reports on round tables, BUP (2013), 2011-2016.

[13] S. Lie, C. Angell \& A. Rohatgi, Interpreting the Norwegian and Swedish trend data for physics in the TIMSS Advanced Study, Nordic Studies in Education, Vol. 32 (2012), 177-195.

[14] L. Viennot \& C. de Hosson, Beyond a dichotomic approach, the case of colour phenomena. International Journal of Science Education, 34:9 (2012), 1315-1336

[15] L. Viennot \& C. de Hosson, From a Subtractive to Multiplicative Approach, A Concept-driven Interactive Pathway on the Selective Absorption of Light, International Journal of Science Education (2014), DOI: 10.1080/09500693.2014.950186

[16] "More Understanding with Simple Experiments", EPS web site, www. EPS.org, Education, MUSE.

[17] L. Viennot. Thinking in Physics, The pleasure of reasoning and understanding in physics. Springer/Grenoble Sciences (2014). 
Conceptual understanding and critical stance

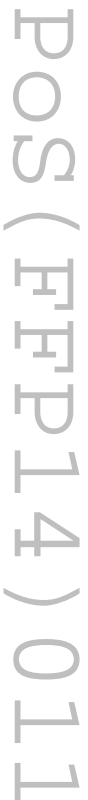

